\title{
Strategic IS Planning Practices: A Case of Medium Manufacturing Company in Malaysia
}

\author{
Raja Haslinda Raja Mohd. Ali ${ }^{*}$, Rosli Mohamad, Yurita Yakimin Abdul Talib, Akilah \\ Abdullah \\ Tunku Puteri Intan Safinaz School of Accountancy (TISSA-UUM), Universiti Utara Malaysia
}

\begin{abstract}
Deployment of Information Technology/Information Systems (IT/IS) has been recognized as one of the potential means to supply information for timely business decision making. Despite growing importance of IT/IS in business, Small Medium Enterprises (SMEs) embrace constant challenges to deploy IS effectively, and thus, hardly to optimize the IT/IS strategic values. In such situation, IS planning is getting paramount to promote more effective IT/IS management of the firms. This study reports IS planning practices of a manufacturing-based SME. The face to face interview has been carried out to explore IS planning activities in a chosen firm. The qualitative analysis suggests that the selected company did undergo the four phases of strategic IS planning process namely, planning, analysing, selection, and implementation. The owner act as the champion of the strategic IS planning process. Further, the owner and the employees plays an important role as a decision maker. Specifically, the owner decides mainly on acquiring a new technology related to the firm's core business process whereas the users responsible on the selection of relevant application (s) to be used in their respective departments. Apart from that, the owner also plays a role as a researcher for the new technology acquired whilst the users provide an input on the applications to be acquired.
\end{abstract}

\section{Background and Objective of Study}

Greater reliance on Information Technology/Information Systems (IT/IS) on daily operations and strategic needs urges today's organisations to emphasise on the IS planning. Appropriate IS planning practice enables organisations to narrow the gap between IT/IS and the strategic objectives of the organisations. IS alignment then leads to a greater competitiveness and value derived from IS-related investment [1].

Increased importance of IT/IS in organisation has attracted considerable research to understand the impact of IT/IS on firm performance. Specifically, IS planning emerges as one of the primary focuses as long as IT/IS deployment is concerned. IS planning refers to a process of specifying an organization's selection of computer-based applications and technologies that correspond to the organisations strategic objectives [2].

* Corresponding author: rj.linda@uum.edu.my 
In contrast to considerable focus on earlier studies of IS planning amongst large organisations, studies involving smaller firms (SMEs) are somewhat limited [3, 4]. Taking into consideration considerable contribution of SMEs in most nations' economy, how these firms embrace IT/IS deserve special attention. More importantly, the firms are facing somewhat unique challenges while embracing IT/IS in optimising IT/IS related values [5]. Among possible explanations are the lack of strategic orientation in their IT/IS deployment [6] and limited resources capabilities, particularly knowledge and skills to plan and manage IS-related projects [7]. Apart from that, management and administration of the firms are more likely on ad-hoc basis and informal in nature [8]. Thus, how the firms plan their IT/IS worth further investigation. In response, this study tries to understand IS planning practices in the context of SMEs with a specific focuses on the role of top management and system user.

This study adapted SISP success model [2] that has been extensively used for large organisation context to establish in-depth understanding of top management role and user involvement in IS planning practice of SMEs. The framework underpins most of the strategic IS planning research. The framework illustrates the strategic IS planning as inputprocess-output model. The input for strategic IS plan comprises of seven components that include environmental factors (both internal and external as well as planning resources), planning process, information plan, plan implementation, alignment (between internal environment and the organisations' strategic goals). Meanwhile IS strategic plan represents the output of the planning process.

\section{Research Method}

Researchers employed qualitative research strategy based on a single case study. A manufacturing firm located in Northern region of Malaysia was identified for this study. A screening process had taken place during the phone call to ensure the firms had employed certain types of IS/IT related applications. Data were obtained via semi-structured themed interview with the owner/manager of the respective firms. Based on the owner/manager consent, another series of interview was carried out involving the system user. An openended interview method allows respondents to express the key issues using their own terms [9]. This enables researchers to systematically accumulate detailed and richer data from the respondents [10].

Data were collected on four main thematic focus; (i) description of IS planning stages and activities that have been applied in a firm based on [11, 12] framework, and (ii) roles of top management and users in IS planning activities. Each interview sessions had taken place for about $1 \frac{1}{2}$ hours. Researchers presented the interview questions in English and digitally recorded the interview session upon obtaining interviewees' permission.

Authors followed [13] guidelines in analysing the qualitative results. The researcher initially listened to the recordings and had them transcribed. The data was divided into units and a meaningful code was assigned to data units one by one. The coding of all units (including the ones set aside in the "miscellaneous" stack) was repeated several times, with codes merged, renamed, and split where appropriate. The second researcher then analysed the data independently to strengthen the credibility of the outcomes. The next section reports data analysis results and discussion of the outcomes.

\section{Findings and Discussion}

Company A is a medium sized firm that was bought over from the in 1995. As time goes by, this factory has grown to become one of the successful medium firm with about 50 
permanent employees. The main business process for Company A is paddy processing and it also acts as a rice supplier. This firm has five interrelated functional departments of purchasing, sales, drying, packaging, and paddy processing. Administrative tasks in the firm mainly involve purchasing and sales as well as production such as processing, drying, packaging, and storage. Some of the systems and machines used in Company A were already there when the company was bought over suggesting more than 20 years of age. However, there are few technologies that were bought within the last five years. Some of the business processes are computerised but some are not. The decision on whether it needs to be computerised depends on the criticality of the business process. For Company A, accounting and manufacturing are two most critical functions. For this company, 50 employees are easily to track and manage, so manual system is still reasonable to be used.

\subsection{Stages in strategic IS planning}

The owner started the process by identifying the issues that they are facing currently. The mentioned issue related to hiring young workers who are willingly to work in a rice factory. Most of their workers are elderly. He stated that,

"It's so difficult to find a worker nowadays. That is why, when you see in my company most of them are elderly, 76 years old, 69 years old also we have."

Further in this stage, the company also aims to reduce the amount of wages. Decision on acquiring a new technology (robotic) is made due to the assumption that the numbers of workers in the factory can be reduced. Before the robotic was acquired, three employees need to be hired to do the task. After the robotic has been acquired, only an employee is needed to do the same job.

Company A, however, did not have a specific period for the planning. When the new technology or systems is needed, then they start the planning process. In addition, the owner believed that there is no need to prepare a planning earlier as the technology growth rapidly.

Next, the owner analysed the external business environment during this stage especially on the supplier credibility and history company background. He mentioned,

"Yes, we do look at their company's objective. We visited the factory...We

have to be really sure about the brand and the plant."

Then, the top management selected the specific technology that is considered the best solution to their knowledge. Once the proposed project is implemented, the business process was changed from manual to fully computerised. For example, the work that was once conducted by three employees, with the implementation of the new technology, only one person is needed by a click of a button. In sum, Company A completed four stages of strategic IS planning process as presented in Figure 1 below.

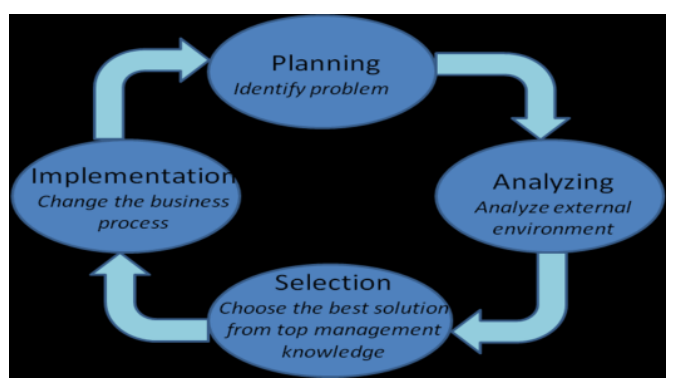

Figure 1: SISP process for Company A 


\subsection{Champion}

The champion of the strategic IS planning process in Company $\mathrm{A}$ is the owner, as the owner decides everything related to acquiring the new information system and technology. The owner asserted,

"Yes, I decide everything, include what to buy. The directors also do not know. I have many directors. What I want to purchase, I need to table everything in the meeting."

The owner decides the technology that the company needed and presented to the board of directors for their approval. This is important to ensure that the board of directors know about the investment to be made.

\subsection{Roles of Top Management in Strategic IS Planning}

This section discusses on the roles of top management in strategic IS planning development. Findings suggested that top management plays an important role in making decision and studying the technology to be acquired.

\subsubsection{Decision maker}

All decision with regards to acquiring the new technology will be made by the owner. When asking whether the owner discussed with his employees about the proposed technology, he asserted,

"The most important is I'm the one who makes the decision. Then I tabled to the board of directors."

However, the employees do assist him on some parts of the decision making process as preparing the proposal and budget. The owner further urged,

"Of course, I get the help from my employee [the accounts executive]. We discussed. I need to use a system to prepare a budget. I don't know. So they [the accounts executive] need to assist me. I do not know how to prepare the paperwork. I only have ideas."

\subsubsection{Researcher}

The owner did some studies about the proposed technology including went for a site visit at the supplier factory. One of the reasons is that he could not rely on his employees as for him the employees do not have knowledge about the proposed technology. He asserted,

"Ooo..they do not know either [about the proposed technology]. Further, during the site visit, only one person can go. As I make the decision, I had to go. Most of my employees, they only know about their daily tasks. I am the one who needs to know everything."

In sum, the top management in Company A plays important role in decision making and collected information with regards to the proposed technology.

\subsection{Roles of Users in Strategic IS Planning}

This section discusses on the roles of users in strategic IS planning development. Findings suggested that users also play important roles in making decision and providing input about the applications to be used or acquired in their respective department. 


\subsubsection{Decision maker}

The decision with regards to the business units will be decided by the business units itself and not the owner. For example, the application used in the accounting department was decided by the Accounts Manager. The owner stated that,

"For example accounts department, they will make their own decision. I do not know about their applications.... the HR manager's refused to use any applications for her department, so I said OK... They know better about their department".

Further, when respondents were asked about the decision made on applications to be used in their department, one of the users assert,

"We make our own decision."

\subsubsection{Input Provider}

The users also provide inputs during the planning stage to make sure that the applications acquired can assist them to do their daily tasks. One of the users explained,

"We are a group of accounts executive that report to a chief accountant at the Head Office... So, we will discuss on what systems that we want to use. Our company (Company A) has its own procedure and its own accounting system. I will assist them [by giving information] on any issues related to the systems such as upgrading the systems..."

In sum, the users play an important role in strategic IS planning. However, their role is limited to the application that is used in their own department only. They did not make any decision nor provide input for the major technology acquired by their organization.

\section{Conclusion}

Every organization will have different phases to develop their strategic IS planning. Some organizations may have completed or undergone all the phases as suggested by the literature. However, some organizations may complete some phases only because it is applicable to the needs and nature of their organization. Company A, a medium-sized manufacturing company only undergone four phases, namely planning, analysing, selection, and implementation. As and when this company face any issues related to the IS and business process in their organization, they will prepare the planning. Therefore, conceiving phase is not been included as they already decided the proposed technology and applications to be acquired.

Further, the results aligned with previous studies on SMEs that the top management is the champion of the strategic IS planning process in which they have the power to make the decision related to the overall organization $[14,15]$. The users will only decide on the specific applications to be used in their respective department. In this study, the owner of Company A did all the studies related to the proposed technology without assistant from his employees. The owner's reluctant to gain assistance from his employees might be due to the reason that, as most of the employees in his company are elderly, they might not have knowledge about the newest technology available in the market.

In conclusion, this study provides a clear understanding on how medium-sized organization practiced IS planning with a specific focuses on the role of top management and system user.

We would like to thank Universiti Utara Malaysia for providing funding on this research project. 


\section{References}

1. V. Basu, E. Hartono, A. L. Lederer, V. Sethi. Inform. Manage. The impact of organisational commitment, senior management involvment, and team involvement on strategic information systems planning. 39, 513-524 (2002)

2. A. L. Lederer, H. Salmela. J. Strategic Inf. Syst. Toward a theory of strategic information systems planning. 5 (3), 237-253 (1996)

3. P. Powell, M. Woerndl. Eur. J. Inform. Syst. Time to stop searching the important things?. 17, 174-178 (2008)

4. A Garg, D. P. Goyal. J. Adv. Manage. Res. Striving towards strategic alignment in SMEs: An empirical analysis. 9 (1), 77-95 (2012)

5. T. Fuller. Int. Small Bus. J. Fulfilling IT needs in small businesses: A recursive learning model. 14 (4), 25-45 (1996)

6. C. Hagmann, C. McCahon. Inform. Manage. Strategic information systems and competitiveness. 25, 183-192 (1993)

7. S. Pavic, S.C.L. Koh, M. Simson, J. Padmore. Benchmarking: An Int. J. Could e-business create competitive advantages in UK's SMEs? 14 (3), 320 - 351 (2007)

8. P. Bharati, A. Chaudhury. Int. J. E-Bus. Res. SMEs and competitiveness: The role of information systems. 5 (1), i - ix (2009)

9. R. S. Y. Berry. Paper presented at the British Educational Research Association Annual Conference, University of Sussex at Brighton. Collecting data by in-depth interviewing. $\begin{array}{lllllll}\text { September } & 2-5 & \text { (1999). } & \text { Retrieved July 1, } 2013 \text { from }\end{array}$ http://www.leeds.ac.uk/educol/documents/000001172.htm

10. J. F. Gubrium, J. A. Holstein (Eds). Handbook of interview research. Thousand Oaks, CA: Sage (2002)

11. H. E. Newkirk, A. L. Lederer, A. M. Johnson. Eur. J. Inf. Syst. Rapid business and IT change: drivers for strategic information systems planning. 17 (3), 198-218 (2008)

12. A Cassidy. A Practical Guide to Information Systems Strategic Planning. Auerbach Publications. NW: Taylor \& Francis Group (2006)

13. D. A. Erlandson, E. L. Harris, B. L. Skipper, S. D. Allen. Doing Naturalistic Inquiry: A Guide to Methods. California: Sage publications (1993)

14. P. Bharati, Chaudhury, A. Commun. ACM. Studying the current status of technology adoption. 49 (10), 88-93 (2006)

15. Chia-An Chao, Aruna Chandra. JSBED. Impact of owner's knowledge of information technology (IT) on strategic alignment and IT adoption in US small firms. 19 (1), 114-131 (2012) 